\title{
Fuzzy-based energy management of a residential electro-thermal microgrid based on power forecasting
}

\author{
Diego Arcos-Aviles \\ Department of Electrical \\ and Electronics Engineering \\ Universidad de las Fuerzas \\ Armadas ESPE \\ Sangolqui, Ecuador \\ dgarcos@espe.edu.ec \\ Rodolfo Gordillo \\ Department of Electrical \\ and Electronics Engineering \\ Universidad de las Fuerzas \\ Armadas ESPE \\ Sangolqui, Ecuador \\ rxgordillo@espe.edu.ec
}

\author{
Francesc Guinjoan \\ Department of Electronics \\ Engineering \\ Universitat Politècnica de \\ Catalunya-Barcelona \\ TECH \\ Barcelona, Spain \\ francesc.guinjoan@upc.edu \\ Pablo Sanchis \\ Department of Electrical \\ and Electronics Engineering \\ Universidad Pública de \\ Navarra \\ Pamplona, Spain \\ pablo.sanchis@unavarra.es
}

\author{
Julio Pascual \\ Department of Electrical \\ and Electronics Engineering \\ Universidad Pública de \\ Navarra \\ Pamplona, Spain \\ juliomaria.pascual@unavarra.es
}

\author{
Martin P. Marietta \\ Department of Electronics \\ Engineering \\ Universitat Politècnica de \\ Catalunya-Barcelona \\ TECH \\ Barcelona, Spain \\ martin.pablo.marietta@upc.edu
}

\author{
Luis Marroyo \\ Department of Electrical \\ and Electronics Engineering \\ Universidad Pública de \\ Navarra \\ Pamplona, Spain \\ luisma@unavarra.es
}

\author{
Alexander Ibarra \\ Department of Electrical \\ and Electronics Engineering \\ Universidad de las Fuerzas \\ Armadas ESPE \\ Sangolqui, Ecuador \\ oaibarra@espe.edu.ec
}

\begin{abstract}
In this paper, an energy management strategy based on microgrid power forecasting is applied to a residential grid-connected electro-thermal microgrid with the aim of smoothing the power profile exchanged with the grid. The microgrid architecture under study considers electrical and thermal renewable generation, energy storage system (ESS), and loads. The proposed strategy manages the energy stored in the ESS to cover part of the energy required by the thermal generation system for supplying domestic hot water to the residence. The simulation results using real data and the comparison with previous strategy have demonstrated the effectiveness of the proposed strategy.
\end{abstract}

Keywords-microgrids, energy management, renewable energy sources, distributed power generation, fuzzy logic control

\section{INTRODUCTION}

The increase in the use of Renewable Energy Sources (RES) has attracted the attention of the research community during the last years [1], since they are inexhaustible at human scale, non-polluting, and provide energy independence and allows the implementation of Distributed Generation (DG) systems [2]. However, their integration with the utility grid in an efficient and reliable manner without excessive investment still remains a challenge.

To overcome this new challenge, Microgrids (MGs) have emerged as an important solution to integrate RES into the electric system. MGs can use different elements, most commonly, RES and energy storage system (ESS), to control the grid power profile [3]. The heart of the MG is the Energy Management System (EMS), which is in charge of controlling the elements belonging to the MG [4]. An adequate strategy linked to the EMS leads to an efficient MG performance. This is the reason that several energy management strategies have been developed in recent years aiming to cover a number of different objectives [5]. In general, the energy management strategy depends on the MG architecture and its goal, which in most cases is related to the microgrid operating cost [6]. However, the suitable control of the grid power profile can concurrently produce an economic benefit of the microgrid and facilitate the grid operator control.

A residential MG scenario has attracted great attention in recent studies [7]-[9]. In this regard, the authors have designed several energy management strategies to smooth the grid power profile of a residential MG being the most relevant [10]-[13]. Two architectures have been studied: electrical $M G$ and electro-thermal MG. The first architecture considers only electrical loads (e.g., household appliances, including space heating and cooling) whereas the second architecture considers also a controllable thermal load, namely, a heater for domestic hot water. In addition, two different scenarios have been studied; a first scenario where power forecasting is not considered and a second scenario considering $\mathrm{MG}$ power forecasting.

In this regard, the study detailed in [14] presents an extension of the fuzzy energy management strategy based on MG energy rate-of-change [12] applied to an electro-thermal MG architecture. This study, [14], considers a local prediction of the battery state-of-charge (SOC) to anticipate the MG future behavior and highlights the advantages of introducing thermal elements in the MG with the aim of improving the grid power profile. Given the positive results obtained in the previous study, this work presents an approach of using the energy management strategy described in [13] applied to a new microgrid power architecture, namely electro-thermal microgrid. This approach extends the study of [14] analyzing the microgrid behavior (i.e., grid power profile smoothing, battery SOC evolution) when a thermal load and microgrid power forecasting is considered in the energy management strategy. 
This paper is organized as follows. Section II describes the MG architecture under study and presents the variable definition of the system. Section III details the design of the fuzzy-based energy management strategy applied to an electrothermal MG. Section IV presents the simulation and comparison results with previous strategy. Finally, Section V presents the main conclusions of this work.

\section{MicROGRID SySTEM ARCHITECTURE}

The residential electro-thermal microgrid under study is presented in Fig. 1 and includes a photovoltaic generator (PV), a wind turbine (WT), an electric ESS consisting of a lead-acid battery bank, a domestic load demand, and a domestic hot water system (DHW), which comprises an electric water heater $(\mathrm{EWH})$, a solar collector array, a thermal demand, and a thermal storage consisting of a hot water tank.

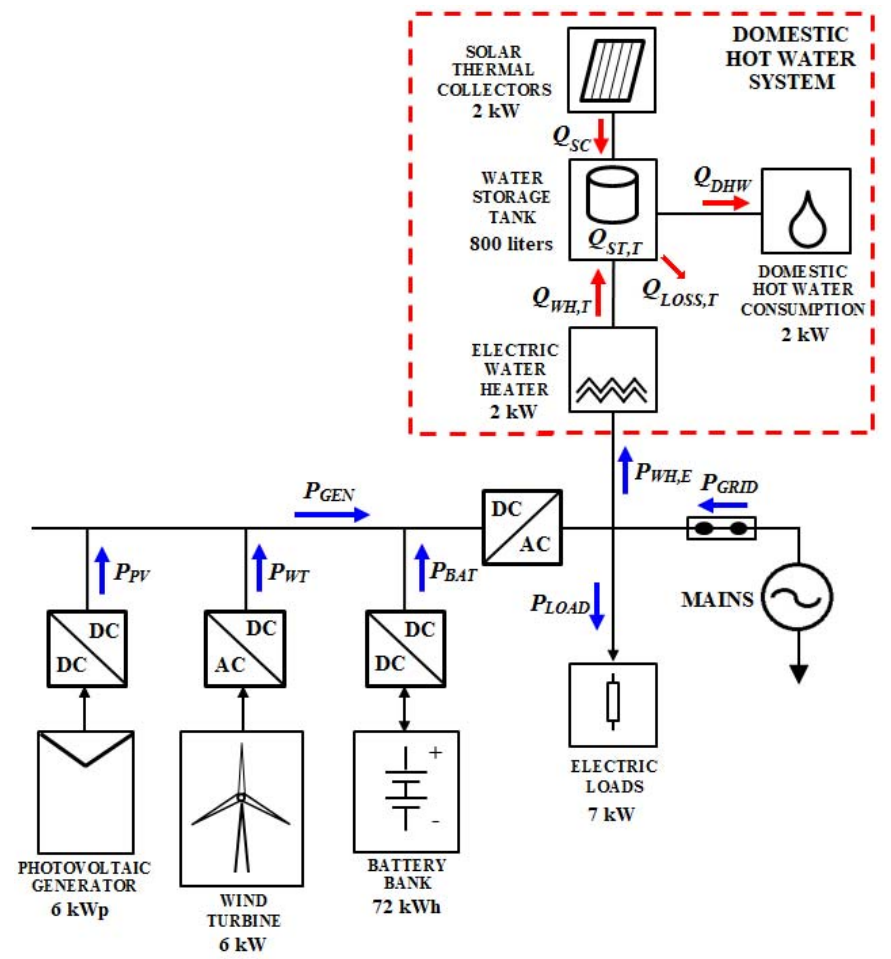

Fig. 1. Residential grid-connected electro-thermal microgrid [14]. (C2016 IEEE, Reprinted, with permission, from D. Arcos-Aviles, D. Sotomayor, J. L. Proano, F. Guinjoan, M. P. Marietta, J. Pascual, L. Marroyo, and P. Sanchis, "Fuzzy energy management strategy based on microgrid energy rate-of-change applied to an electro-thermal residential microgrid," in 2017 IEEE 26th International Symposium on Industrial Electronics (ISIE), 2017, pp. 99-105.

From configuration shown in Fig. 1, the following expressions can be deduced:

$$
\begin{gathered}
P_{G E N}=P_{P V}+P_{W T} \\
P_{G R I D}=P_{L O A D}+P_{W H, E} \quad P_{G E N} \quad P_{B A T}
\end{gathered}
$$

where $P_{G E N}$ is the renewable power generation, $P_{P V}$ is the photovoltaic power, $P_{W T}$ is the wind power, $P_{B A T}$ is the battery power (i.e., $P_{B A T}>0$ for discharging process and $P_{B A T}<0$ for charging process), $P_{\text {GRID }}$ is the power exchanged with the grid (i.e., $P_{G R I D}>0$ for power absorbed from the grid and $P_{G R I D}<0$ for power injected in the grid), and $P_{W H, E}$ is the power required by the EWH to keep the water temperature in the deposit tank between $45^{\circ} \mathrm{C}$ and $65^{\circ} \mathrm{C}[14]$.

Defining the MG net power as:

$$
P_{L G}=P_{L O A D}+P_{W H, E} \quad P_{G E N}
$$

the grid power profile (2) can be rewritten as:

$$
P_{G R I D}=P_{L G} \quad P_{B A T}
$$

Moreover, considering the DHW system shown in Fig. 1, the thermal balance of the storage tank could be defined as:

$$
Q_{S T, T}=Q_{S C}+Q_{W H, T} \quad Q_{D H W} \quad Q_{L O S S, T}
$$

where $Q_{S T, T}$ is the thermal storage capacity of the water storage tank, $Q_{D H W}$ is the house DHW consumption, $Q_{L O S S, T}$ represents the thermal losses in the storage tank, $Q_{S C, T}$ is the rate of energy collected from the solar thermal collectors, and $Q_{W H, T}$ is the rate of energy transferred from the EWH. A detailed description of these variables and their calculation are presented in [14].

Furthermore, in an electro-thermal microgrid scenario the thermal storage, i.e., water deposit tank in this case, is responsible of improving the system performance under sudden peak loads or loss of solar input [15], since it gives another degree of freedom for controlling the system. In this regard, the water temperature inside the thermal storage is needed in order to simulate the EWH control. The current water temperature is calculated as follows:

$$
T_{W D}=T_{W D, 1}+\frac{T_{s}}{{ }_{W} C_{P} V} Q_{S T, T}
$$

where $T_{W D}$ is the current water temperature $\left({ }^{\circ} \mathrm{C}\right)$ in the deposit tank after sampling period $T_{s}, T_{W D,-1}$ is the water temperature ( ${ }^{\circ} \mathrm{C}$ ) of previous sampling period $T_{s},{ }_{W}$ is the water density $\left(\mathrm{kg} / \mathrm{m}^{3}\right), C_{P}$ is the water specific heat capacity $\left(\mathrm{kJ} / \mathrm{kg} \cdot{ }^{\circ} \mathrm{C}\right)$, and $V$ is the storage tank volume $\left(\mathrm{m}^{3}\right)$.

\section{FuZZY-BASED ENERGy MANAGEMENT STRATEGY}

The energy management strategy presented in this work tries to extend the study presented in [13], [16] for the case of an electro-thermal microgrid. The goal still remains the same, i.e., to smooth the power exchanged with the grid, now with the help of the energy stored in the battery ESS to cover part of the energy required by the EWH for keeping the water temperature in the tank between maximum and minimum temperatures.

In this regard, as well as previous studies [13], [16], the power exchanged with the grid is defined as the sum of three components, as follows:

$$
P_{G R I D}(n)=P_{C T R}^{*}(n)+P_{S O C}(n)+P_{F L C}(n)
$$

where $P_{C T R}^{*}$ establishes the $\mathrm{MG}$ average power profile, $P_{S O C}$ tries to keep the battery SOC center close to the $75 \%$ of the rated battery capacity, and $P_{L F C}$ improves the grid power profile according to the battery SOC and the MG forecast error. 
The block diagram of the proposed Fuzzy-based energy management strategy is presented in Fig. 2. Note that in this study, the EWH operates as a passive load and it will beyond the control of the energy management strategy. In this context, the EWH consumption, $P_{W H, E}$, is obtained through a hysteresis control to keep water temperature in the tank between $45{ }^{\circ} \mathrm{C}$ and $65^{\circ} \mathrm{C}$. The description blocks depicted in Fig. 2 is presented next.

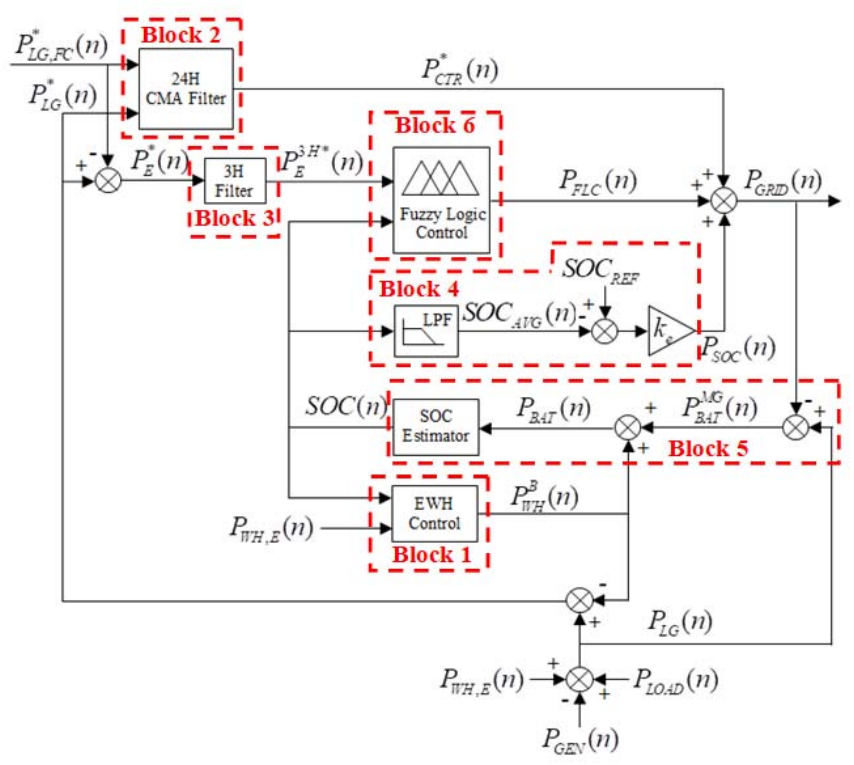

Fig. 2. Residential grid-connected electro-thermal microgrid

\section{A. Block 1-EWH Control}

This block is used in [14] to compute the amount of energy contributed by the battery for the EWH consumption, $P_{W H}^{B}(n)$. Considering a battery threshold, $S O C_{R}$, for power injection from the battery to the EWH, $P_{W H}^{B}(n)$ is assigned as follows:

$$
P_{W H}^{B}(n)=\left\{\begin{array}{c}
P_{W H, E}(n), \text { if } \operatorname{SOC}(n)>S O C_{R} \& P_{W H, E}(n)>0 \\
0, \text { otherwise }
\end{array}\right.
$$

Consequently, the MG net power (3) is reduced as follows:

$$
P_{L G}^{*}(n)=P_{L G}(n) \quad P_{W H}^{B}(n)
$$

\section{B. Block $2-C M A$ filter}

This block computes the first component, $P_{C T R}^{*}$, of the grid power profile through a 24-hours Central Moving Average (CMA) filter [13], [16], [17], considering the modified MG net power, $P_{L G}^{*}(n)$, and the modified forecast of the MG net power, $P_{L G, F C}^{*}(n)$. The CMA filter uses $P_{L G}^{12 H^{*}}(n)$ of the previous 12-hours and $P_{L G, F C}^{12 H^{*}}(n)$ for the next 12-hours to estimate the MG net power average [13], [16]. Being $M_{12}$ the number of samples in 12-hours, $P_{C T R}^{*}$ is computed as follows:

$$
P_{C T R}^{*}(n)=\left[P_{L G}^{12 H^{*}}(n)+P_{L G, F C}^{12 H^{*}}(n)\right] / 2
$$

$$
\begin{gathered}
P_{L G}^{12 H^{*}}(n)=\frac{1}{M_{12}} \sum_{k=1}^{M_{12}} P_{L G}^{*}\left(\begin{array}{ll}
n & k
\end{array}\right) \\
P_{L G, F C}^{12 H^{*}}(n)=\frac{1}{M_{12}} \sum_{k=1}^{M_{12}} P_{L G, F C}^{*}(n+k)
\end{gathered}
$$

Similarly to $P_{L G}$, the use of the battery energy to supply part of the power required by the EWH implies a reduction of the MG load demand. Therefore, the load demand and consequently the forecast of the MG net power (i.e., $P_{L O A D}^{*}(n)$ and $P_{L G, F C}^{*}(n)$, respectively) are modified as follows:

$$
\begin{gathered}
P_{L O A D}^{*}(n)=P_{L O A D}(n) \quad P_{W H}^{B}(n) \\
P_{L G, F C}^{*}(n)=P_{L O A D, F C}^{*}(n) \quad P_{G E N, F C}(n)
\end{gathered}
$$

Note that the renewable power generation is not affected by the use of the EWH, thus, the forecast of power generation, $P_{G E N, F C}$, is maintained. Fig. 3 presents the block diagram of the $\mathrm{MG}$ net power forecast where both the renewable power generation and load forecasts are estimated using the $\mathrm{MG}$ power forecasting procedure presented in [13].

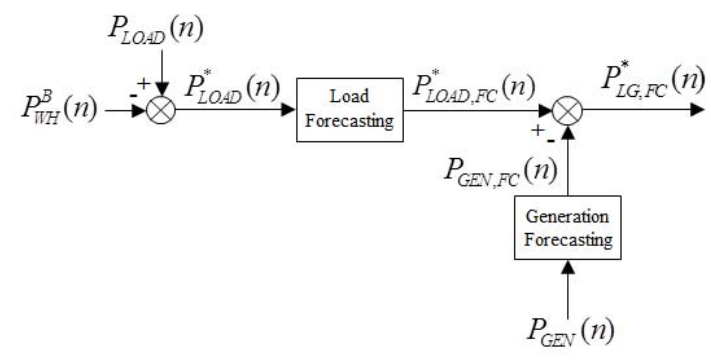

Fig. 3. Block diagram of the Microgrid net power forecast

\section{Block $3-3$ H filter}

This block computes the MG power forecast error of the previous 3-hours (being $M_{3}$ the number of samples in 3-hours) considering the modified MG net power and its forecasted value, as follows:

$$
\begin{aligned}
& P_{E}^{3 H^{*}}(n)=\frac{1}{M_{3}} \sum_{k=1}^{M_{3}} P_{E}^{*}\left(\begin{array}{ll}
n & k
\end{array}\right) \\
& P_{E}^{*}(n)=P_{L G}^{*}(n) \quad P_{L G, F C}^{*}(n)
\end{aligned}
$$

\section{Block 4-LPF}

Similarly to the energy management strategy described in [13], [16], this block is used to compute the second component, $P_{S O C}$, of the grid power profile. which is in used to keep the battery SOC center close to the $75 \%$ of the rated battery capacity, $C_{B A T}$, [11], [13], [16]. As it can be seen in Fig. 3, $P_{S O C}$ is proportional to the error between a SOC reference, $S O C_{R E F}=75 \%$, and the average SOC of the previous 24-hours, $S O C_{A V G}$, as follows:

$$
P_{S O C}(n)=k_{e}\left[S O C_{R E F} \quad S O C_{A V G}(n)\right]
$$




$$
\operatorname{SOC}_{A V G}(n)=\frac{1}{M_{24}} \sum_{k=1}^{M_{24}} \operatorname{SOC}\left(\begin{array}{ll}
n & k
\end{array}\right)
$$

where $M_{24}$ is the number of samples in 24-hours and $k_{e}$ is the proportional gain constant, which is set $k_{e}=0.05 \mathrm{~kW} / \%$ according to [11], [13], [16].

\section{E. Block 5-SOC Estimator}

This block is used to estimate the SOC of the ESS for simulations purposes. This estimator has been extensively described in [12]-[14], [16]. In short, the current battery SOC, SOC $(n)$, is obtained considering the previous battery charge, $S O C(n-1)$ and the battery SOC variation during the sampling period $T_{s}, \triangle S O C(n)$, as follows:

$$
\begin{aligned}
& \operatorname{SOC}(n)=\operatorname{SOC}\left(\begin{array}{ll}
n & 1
\end{array}\right) \quad \operatorname{SOC}(n) \\
& \operatorname{SOC}(n)=\left(100 / C_{B A T}\right) \quad P_{B A T}\left(\begin{array}{ll}
n & 1
\end{array}\right) T_{s} \\
& P_{B A T}(n)=P_{B A T}^{M G}(n)+P_{W H}^{B}(n) \\
& P_{B A T}^{M G}(n)=P_{L G}(n) \quad P_{G R I D}(n)
\end{aligned}
$$

Note that different battery efficiencies are considered, i.e., ${ }_{C}$ and ${ }_{D}$, for battery charging and discharging processes, respectively. Additionally, battery SOC should satisfy the constrains defined in [13], this is, $S O C_{M I N} \leq S O C(n) \leq S O C_{M A X}$, $S O C_{M I N}=(1-D O D) \cdot S O C_{M A X}$ considering a maximum the Depth of Discharge (DOD) of $50 \%$.

\section{F. Block 6-Fuzzy Logic Control}

This block is used to compute the third component, $P_{F L C}$, of the grid power profile. This component is used to improve the power exchanged with the grid according to the battery SOC and the MG power forecast error of the previous 3-hours [13], [16]. The FLC assumes a Mamdani-based inference and Center of Gravity defuzzification [18] with two-inputs, one-output, and 25-rules. The FLC design procedure: selection of five Membership Functions (MF) for each input, nine MF for the output, its type (i.e., triangular) and mapping, is the same of the one presented in [13], [16].

All fuzzy logic parameters, such as MFs and mapping, are adjusted in order to minimize a set of quality criteria defined in [12], [13]. The off-line adjustment follows the procedure described in [19]. It makes use of real data (i.e., PV, WT, and load power) measured along one year in the microgrid installed at Public University of Navarre (UPNa), Pamplona, Spain, to train the FLC. In short, the adjustment procedure includes the following steps: a) initial FLC design setting (i.e., set the MFS of inputs and outputs, set the initial fuzzy rule-base which is created according to the heuristic knowledge about the MG behavior), b) adjust the inputs and outputs MFs and the initial rule-base to minimize the quality criteria defined in [12], [13].

Thus, given the new objective of the energy management strategy, the adjustment procedure [19] establishes an output variation range of the FLC between $P_{N}=-0.8 \mathrm{~kW}$ and $P_{P}=1.35 \mathrm{~kW}$ (Fig. 4). In addition, the adjustment procedure leads a set of rules that minimizes the quality criteria defined in [11]-[13], which is presented in TABLE I.

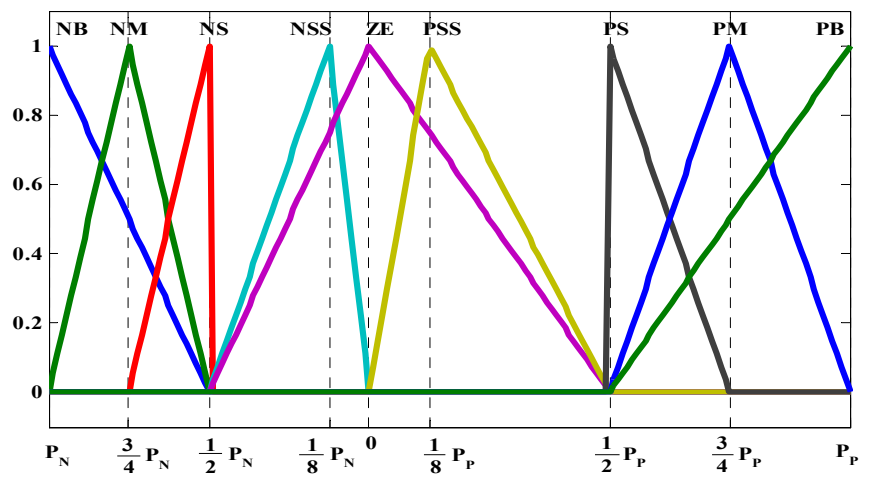

Fig. 4. Membership functions for the FLC output [16]. (C2016 IEEE, Reprinted, with permission, from Arcos-Aviles D, Guinjoan F, Marietta MP, Pascual J, Marroyo L, Sanchis P. Energy management strategy for a grid-tied residential microgrid based on Fuzzy Logic and power forecasting. IECON 2016 - 42nd Annu. Conf. IEEE Ind. Electron. Soc., Florence, Italy: IEEE; 2016, p. 4103-8

TABLE I. FLC RULE-BASE

\begin{tabular}{||c|c|c|c|c|c|c||}
\hline \multirow{2}{*}{} & \multicolumn{5}{|c||}{$\boldsymbol{P}_{\text {FLC }}^{3 H^{*}}(\boldsymbol{n})$} \\
\cline { 3 - 8 } & NB & NS & ZE & PS & PB \\
\hline \multirow{4}{*}{ SOC (n) } & NB & PB & PM & PS & PM & PB \\
\cline { 2 - 8 } & NS & PM & PS & PSS & PS & PM \\
\cline { 2 - 8 } & ZE & NS & ZE & ZE & PSS & NSS \\
\cline { 2 - 8 } & PS & NM & NS & NSS & NS & NM \\
\cline { 2 - 8 } & PB & NB & NSS & NM & NM & NB \\
\hline
\end{tabular}

\section{Simulation RESUlts AND ANALYSIS}

Using real data from July 2013 to July 2014 provided by Public University of Navarre (UPNa), the results are obtained through numerical simulations using MATLAB $\AA$. The main objective of the proposed strategy is using the energy stored in the ESS to supply part of the energy required by the EWH and to improve the grid power profile. The use of battery power to supply part of the energy required by the EWH reduces the total load, coming from the mains, required by the $\mathrm{MG}$, as shown in Fig. 5(a). Hence, the strategy modifies the load demand forecast considering the modified load demand, which leads to decrease the load forecast, as can be appreciated in Fig. 5(b). Consequently, the MG net power and its forecasts are modified, as displayed in Fig. 5(c) and Fig. 5(d) respectively.

To highlight the advantages of the proposed strategy, a comparison with energy management strategy presented in [14], hereinafter referred to EMS1, is presented next. Fig. 6 shows the grid power profile comparison between EMS1 and the proposed strategy. As it can be seen, the proposed strategy minimizes the grid power fluctuations achieving a maximum power injected by the grid of $2.563 \mathrm{~kW}$ and a maximum power absorbed by the grid of $-1.892 \mathrm{~kW}$. Note that the negative sign in the grid power profile implies power injection from the $\mathrm{MG}$ to the mains. 


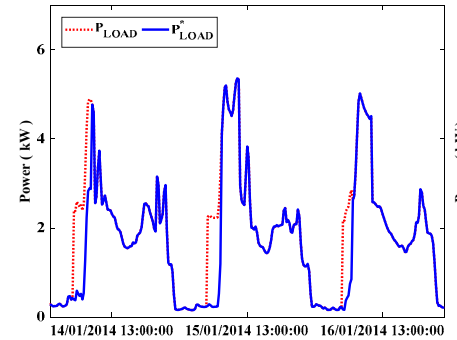

(a)

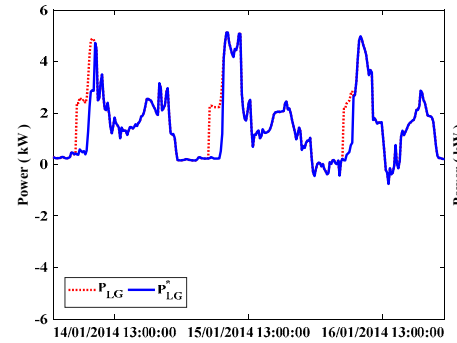

(c)

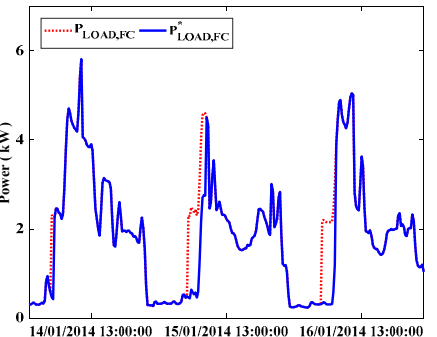

(b)

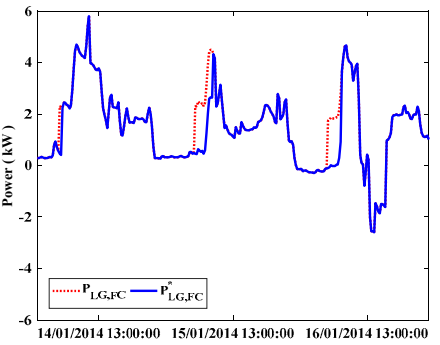

(d)
Fig. 5. MG original and modified variables comparison (a) load demand, (b) load demand forecast, (c) MG net power, and (d) MG net power forecast.

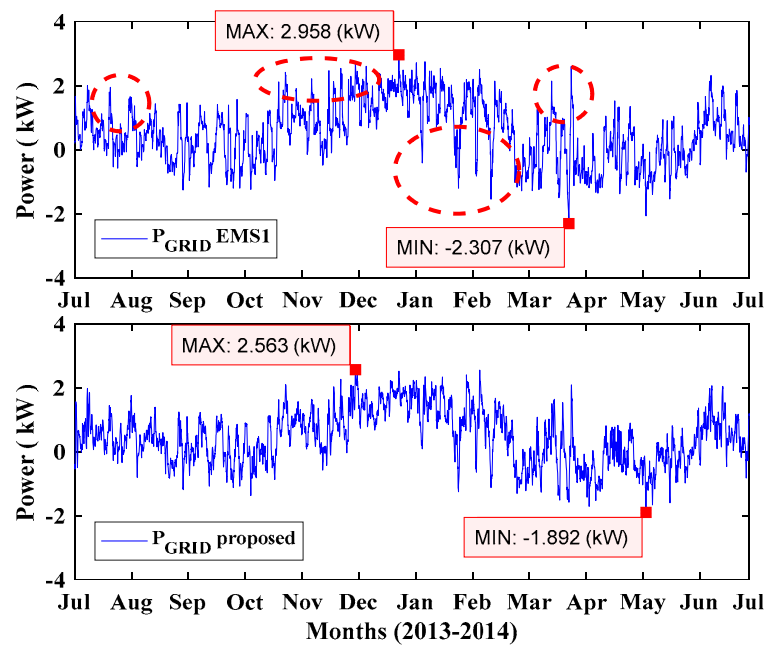

Fig. 6. Grid power profile comparison between energy management strategy EMS1 and the proposed strategy.

The improved grid power profile is evidenced when comparing the grid power profile ramp-rates (i.e., the slope in two consecutive samples) achieved by the EMS1 and the proposed strategy. As it can be seen in Fig. 7 the slopes in the grid power profile are reduced by the proposed strategy reaching a maximum value of $846 \mathrm{~W} / \mathrm{h}$ in the year under study (1052 W/h for EMS1).

In addition, Fig. 8(a) and Fig. 8(b) present the battery SOC and the daily average SOC profile comparison, respectively, between the EMS1 and the proposed strategy. As shown in Fig. 8(a), the battery SOC achieved by the proposed strategy is close centered to the battery SOC reference $(75 \%$ of the rated battery capacity), which can be noticeably appreciated when analyzing the daily average SOC profile presented in Fig. 8(b). Moreover, the improved battery SOC evolution of the proposed strategy can be evidenced in Fig. 9, where it can be noted that the battery SOC is kept in a range between $70 \%$ and $80 \%$ of the rated battery capacity during the $45.83 \%$ of the year under study. Conversely, the EMS1 keeps the battery SOC in this range the $36.96 \%$ of the year. This enhanced behavior causes the battery to be prepared to compensate the grid power fluctuations that may presents in the MG.

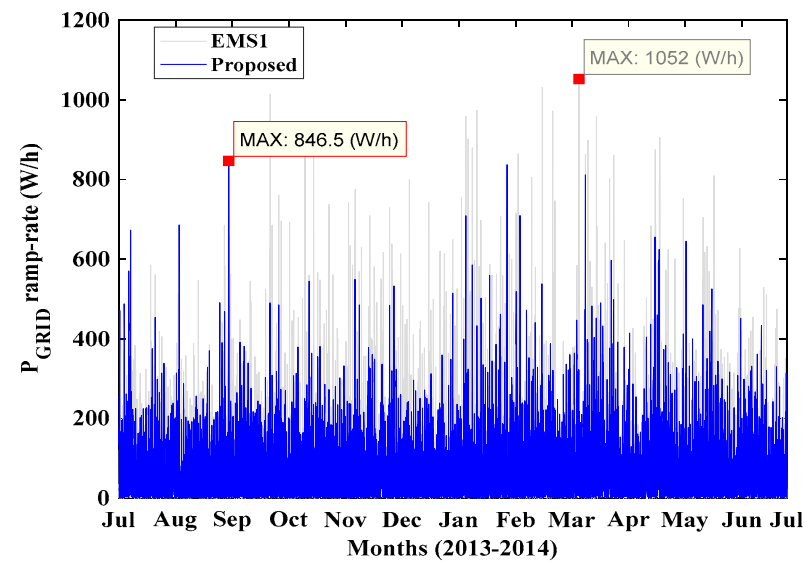

Fig. 7. Maximum grid power profile ramp-rate achieved by the proposed strategy.
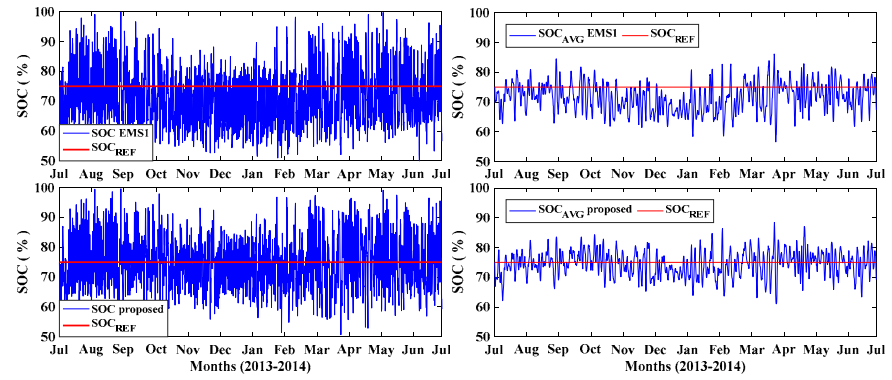

Fig. 8. (a) Battery SOC comparison. (b) Daily average SOC profile comparison.

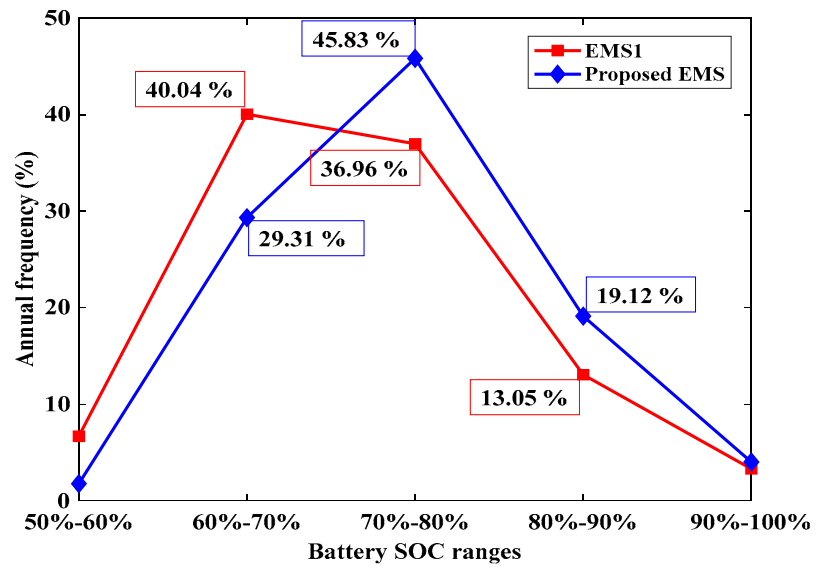

Fig. 9. Histogram of the battery SOC ranges achieved by the EMS1 and the proposed strategy.

In relation to the energy saved obtained by applying the proposed strategy in an electro-thermal MG scenario, it can be observed in Fig. 10 that the battery ESS contributes with the 
EWH load consumption to keep the water temperature in the deposit tank in a range between $45{ }^{\circ} \mathrm{C}$ to $65^{\circ} \mathrm{C}$. In the year under study, the energy supplied by the ESS reaches $318.5 \mathrm{kWh}$, which represents an energy saving of $18.5 \%$ in the MG energy consumption.

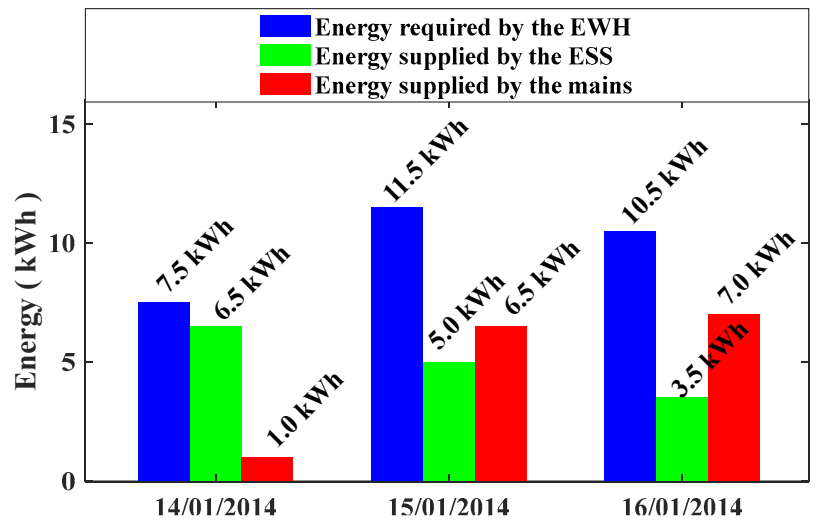

Fig. 10. Distribution of the energy required by the EWH between the battery ESS and the mains for three consecutive days.

\section{CONCLUSIONS}

The fuzzy energy management strategy based on microgrid power forecasting applied to an electro-thermal microgrid scenario has been presented in this study. The proposed strategy has improved the grid power profile and the battery SOC evolution with respect to previous work where microgrid power forecast is not considered. The proposed strategy has minimized power fluctuation in the grid power profile achieving a maximum power fed into the grid of $1.89 \mathrm{~kW}$ and a maximum power injected by the grid of $2.56 \mathrm{~kW}$. In addition, the enhanced behavior of the proposed strategy has improved the battery SOC evolution in the year under study where the battery has kept the $45.8 \%$ of the year in a range between $70 \%$ and $80 \%$ of the rated battery capacity. Finally, the use of thermal elements within the microgrid has contributed with the reduction of the $18.5 \%$ of the total energy required by the microgrid reducing its operating costs. Future work will be focus on changing the controller's philosophy to smooth the grid power profile considering restrictions imposed by the grid operator and demand side management.

\section{ACKNOWLEDGMENT}

This work is part of the project 2016-PIC-044 and 2018-REV-003 from the Research Group of Propagation, Electronic Control, and Networking (PROCONET) of Universidad de las Fuerzas Armadas ESPE. This work has been partially supported by the Spanish Ministry of Science, Innovation and Universities: grants DPI2013-41224-P, DPI2015-67292, DPI2016-80641-R, and DPI2017-85404-P.

\section{REFERENCES}

[1] REN21, "Renewables 2017 Global Status Report," (Paris: REN21 Secretariat), 2017.
[2] L. Bartolucci, S. Cordiner, V. Mulone, V. Rocco, and J. L. Rossi, "Renewable source penetration and microgrids: Effects of MILP - Based control strategies," Energy, vol. 152, pp. 416-426, Jun. 2018.

[3] R. H. Lasseter, "MicroGrids," in IEEE Power Engineering Society Winter Meeting, Jan. 2002, vol. 1, pp. 305-308.

[4] S. K. Sahoo, A. K. Sinha, and N. K. Kishore, "Control Techniques in AC, DC, and Hybrid AC-DC Microgrid: A Review," IEEE J. Emerg. Sel. Top. Power Electron., vol. 6, no. 2, pp. 738-759, Jun. 2018.

[5] L. Olatomiwa, S. Mekhilef, M. S. Ismail, and M. Moghavvemi, "Energy management strategies in hybrid renewable energy systems: A review," Renew. Sustain. Energy Rev., vol. 62, pp. 821-835, Sep. 2016.

[6] S. S. Reddy, "Optimal scheduling of thermal-wind-solar power system with storage," Renewable Energy, vol. 101, pp. 1357-1368, Feb. 2017.

[7] A. Anvari-Moghaddam, G. Mokhtari, and J. M. Guerrero, "Coordinated Demand Response and Distributed Generation Management in Residential Smart Microgrids," in Energy Management of Distributed Generation Systems, InTech, Jun. 2016, pp. 27-57..

[8] C. Lebron, F. Andrade, E. O'Neill, and A. Irizarry, "An intelligent Battery management system for home Microgrids," in 2016 IEEE Power \& Energy Society Innovative Smart Grid Technologies Conference (ISGT), Minneapolis, MN, USA, Sep. 2016, pp. 1-5.

[9] A. Anvari-Moghaddam, J. M. Guerrero, J. C. Vasquez, H. Monsef, and A. Rahimi-Kian, "Efficient energy management for a grid-tied residential microgrid," IET Gener. Transm. Distrib., vol. 11, no. 11, pp. 2752-2761, Aug. 2017.

[10] J. Pascual, P. Sanchis, and L. Marroyo, "Implementation and Control of a Residential Electrothermal Microgrid Based on Renewable Energies, a Hybrid Storage System and Demand Side Management," Energies, vol. 7, no. 1, pp. 210-237, Jan. 2014.

[11] J. Pascual, J. Barricarte, P. Sanchis, and L. Marroyo, "Energy management strategy for a renewable-based residential microgrid with generation and demand forecasting," Appl. Energy, vol. 158, pp. 12-25, Nov. 2015.

[12] D. Arcos-Aviles, J. Pascual, L. Marroyo, P. Sanchis, and F. Guinjoan, "Fuzzy Logic-Based Energy Management System Design for Residential Grid-Connected Microgrids," IEEE Trans. Smart Grid, vol. 9, no. 2, pp. 530-543, Mar. 2018.

[13] D. Arcos-Aviles, J. Pascual, F. Guinjoan, L. Marroyo, P. Sanchis, and M. P. Marietta, "Low complexity energy management strategy for grid profile smoothing of a residential grid-connected microgrid using generation and demand forecasting," Appl. Energy, vol. 205, pp. 69-84, Nov. 2017.

[14] D. Arcos-Aviles, D. Sotomayor, J. L. Proano, F. Guinjoan, M. P. Marietta, J. Pascual, L. Marroyo, and P. Sanchis, "Fuzzy energy management strategy based on microgrid energy rate-of-change applied to an electro-thermal residential microgrid," in 2017 IEEE 26th International Symposium on Industrial Electronics (ISIE), Edinburgh, UK, Jun. 2017, pp. 99-105.

[15] S. A. Kalogirou, Solar Energy Engineering Processes and Systems. Burlington, MA, EEUU: Elsevier, 2009.

[16] D. Arcos-Aviles, F. Guinjoan, M. P. Marietta, J. Pascual, L. Marroyo, and P. Sanchis, "Energy management strategy for a grid-tied residential microgrid based on Fuzzy Logic and power forecasting," in IECON 2016 - 42nd Annual Conference of the IEEE Industrial Electronics Society, Florence, Italy, Oct. 2016, pp. 4103-4108.

[17] C. Vamos and M. Craciun, "Noise Smoothing," in Automatic Trend Estimation, C. Vamos and M. Craciun, Eds. Dordrecht: Springer Netherlands, 2012, pp. 43-59.

[18] K. Passino and S. Yurkovich, "Fuzzy Control," in Addisson-Wesley, 2010, pp. 55-1-55-27.

[19] D. A. Aviles, F. Guinjoan, J. Barricarte, L. Marroyo, P. Sanchis, and H. Valderrama, "Battery management fuzzy control for a grid- tied microgrid with renewable generation," in IECON 2012 - 38th Annual Conference on IEEE Industrial Electronics Society, Montreal, QC, Canada, Oct. 2012, pp. 5607-5612. 